\title{
Prevalence of autoimmune disorders in pediatrics type- 1 diabetes mellitus in western, Uttar Pradesh, India
}

\section{Manish Gutch, Sukriti Kumar', Sanjay Saran, Keshav Kumar Gupta, Syed Mohd Razi, Rajeev Philip}

Department of Endocrinology, LLRM Medical College, Meerut, ${ }^{1}$ Department of Radiodiagnosis, SGPGI, Lucknow, Uttar Pradesh, India

Address for the Correspondence: Dr. Manish Gutch, D-15, LLRM Medical College, Meerut - 250 004, Uttar Pradesh, India. E-mail: manish07gutch@gmail.com

\begin{tabular}{|l|} 
Access this article online \\
Website: www.ijmedph.org \\
DOI: 10.4103/2230-8598.151246 \\
Quick response code: \\
\hline
\end{tabular}

Background: Various autoimmune disorders are associated with pediatric-type-1 diabetes mellitus (DM), but are usually ill-defined and not usually suspected until the disease becomes advanced, and the prevalence of these autoimmune conditions is usually not very well defined in developing part of the world. Aim: To find out the prevalence of various autoimmune disorders associated with pediatric-type- 1 DM. Materials and Methods: Total of 164 patients were screened $(90$ males and 74 females) during the study period of 1-year, patients were evaluated for the clinical signs, biochemical investigations and family history of autoimmune disorders in a tertiary health care center in western Uttar Pradesh. Results: Autoimmune thyroiditis was found to be most commonly associated with type- 1 diabetes, followed by the celiac disease, and Graves' disease, others less commonly seen were pernicious anemia, juvenile rheumatoid arthritis and vitiligo. Conclusion: Autoimmune hypothyroidism was found to be significantly associated with type-1 diabetes, timely identification of these disorder are of paramount important for better glycemic control and to reduced the morbidity and mortality associated with the conditions.

Key words: Autoimmune thyroiditis, celiac disease, pernicious anemia, type-1 diabetes mellitus

\section{INTRODUCTION}

Type-1 diabetes mellitus (DM) is a common autoimmune disorder of pediatrics population, and it is frequently associated with other autoimmune conditions, especially with autoimmune hypothyroidism with the prevalence varying from $30 \%$ to $40 \%$ in Indian context. ${ }^{[1]}$ Because of high prevalence of autoimmune hypothyroidism, American Diabetes Association (ADA) recommends routine screening at the time of diagnosis of type- 1 diabetes. Celiac disease is also frequently associated with type-1 diabetes, but less frequently than autoimmune thyroiditis. Its prevalence in children and adolescents with type-1 diabetes ranges from $5 \%$ to $7 \%,{ }^{[2]}$ the metabolic control is usually poor with frequent episodes of hypoglycemia. ADA recommends screening for celiac disease in patients with type-1 DM. Other less common manifestations are Graves's disease, pernicious anemia, juvenile rheumatoid arthritis and vitiligo. ${ }^{[3]}$ Hence, far no study has been done in western Uttar Pradesh.

\section{MATERIALS AND METHODS}

A total of 164 children and adolescents with type- 1 diabetes, aged $<18$ years, presenting to the endocrine outpatient department or admitted to the ward of endocrinology and metabolism, were enrolled in the study after taking informed consent. Patients were evaluated clinically; biochemically and inquired about family history of autoimmune disorders, during the study period of 1-year from July 2012 to June 2013. Serum thyroid-stimulating hormone (TSH) was assessed in all patients, by the chemiluminescence method, using a commercial kit. Goiter was assessed, and graded as per the WHO grading system. ${ }^{[4]}$ The diagnosis of celiac disease was made as per the ESPGHAN diagnostic criteria. Blood samples were collected for: Anti-tissue transglutaminase (T'TG) immunoglobulin subclass A using enzyme linked immunesorbent assay, Endoscopic duodenal biopsies were undertaken, in patients negative for anti-TTG antibody, after 
informed consent. Screening for other autoimmune disorders was done only when sign or symptoms or family history suggestive of disorder were present. No statistical analysis was done due to cross sectional study design.

\section{RESULTS}

One hundred and sixty four children with type-1 DM were enrolled in the study. The children comprised of 90 boys and 74 girls. The age ranged from 2.5 years to 18 years (mean age \pm standard deviation $-11.5 \pm 6.4$ ), the age at diagnosis of type-1 diabetes (years) was found to be $9.6 \pm 6.2$, while duration of diabetes varying from newly diagnosed to 12 years. Patients who refused to give consent, where excluded from the study. Detail clinical examination was done to detect goitre, alopecia, vitiligo, joint complaints followed by appropriate biochemical investigation were done.

In our study, the male to female ratio was found to be 1.2:1. The sex wise distribution of the various autoimmune disorders in our type I diabetes patients is given in Table 1.

- $\quad$ Autoimmune hypothyroidism were found in 07 males $(7.7 \%)$ and 21 females $(28.3 \%)$.

- Celiac disease was found in 03 males $(3.3 \%)$ and 2 females $(2.7 \%)$.

- Grave's disease was found in 01 males (1.1\%) and 2 females $(2.7 \%)$.

- Pernicious anemia was found in 01 males (1.1\%) and 1 females $(1.3 \%)$.

- Juvenile rheumatoid arthritis was found in only 01 male $(1.1 \%)$.

- Vitiligo was found only in 03 males $(3.3 \%)$.

In our patients we were unable to detect the cases of alopecia, immune thrombocytopenic purpura and myasthenia gravis.

In addition two females were diagnosed with goitre without the elevation of TSH; none of them had any symptoms on detailed history, and were above the $3^{\text {rd }}$ percentile for height and weight, as per current Indian charts. On examination, none of the boys had a palpable or visible goiter.

\begin{tabular}{lcc}
$\begin{array}{l}\text { Table 1: Autoimmune disorder associated } \\
\text { with type-1 DM }\end{array}$ & Males (90 males) & $\begin{array}{c}\text { Females } \\
\text { (74 females) }\end{array}$ \\
\hline Parameters & 07 & 21 \\
\hline Autoimmune hypothyroidism & 03 & 02 \\
Celiac diseases & 01 & 02 \\
Grave's diseases & 01 & 01 \\
Pernicious anemia & 01 & 00 \\
Juvenile rheumatoid arthritis & 03 & 00 \\
Vitiligo & 00 & 00 \\
Alopecia & 00 & 00 \\
Immune thrombocytopenic purpura & 00 & 00 \\
Myasthenia gravis &
\end{tabular}

DM = Diabetes mellitus 
The association with juvenile rheumatoid arthritis and type-1 diabetes is very rare, and it is mostly reported in cases, ${ }^{[10]}$ in the present study only one child was found to be having juvenile rheumatoid arthritis.

Vitiligo is an acquired disorder resulting in loss of melanocytes which leads to white spots or leukoderma. Vitiligo is frequently associated with other autoimmune disorders like type-1 diabetes, autoimmune thyroiditis, celiac diseases etc., vitiligo was found in $6 \%$ of type- 1 diabetic patients..$^{[1]}$

In the present study we did not find any patient with alopecia, immune thrombocytopenic purpura and myasthenia gravis while incidentally during the enrollment we found one patient of myasthenia gravis is association with autoimmune hypothyroidism.

\section{REFERENCES}

1. Kalra S, Kalra B, Chatley G. Prevalence of hypothyroidism in pediatric type-1 diabetes mellitus in Haryana, Northern India. Thyroid Res Pract 2012;9:12-4.

2. Acerini CL, Ahmed ML, Ross KM, Sullivan PB, Bird G, Dunger DB. Coeliac disease in children and adolescents with IDDM: Clinical characteristics and response to gluten-free diet. Diabet Med 1998;15:38-44.

3. Betterle C, Zanette F, Pedini B, Presotto F, Rapp LB, Monciotti CM, et al. Clinical and subclinical organ-specific autoimmune manifestations in type 1 (insulin-dependent) diabetic patients and their first-degree relatives. Diabetologia 1984;26:431-6.
4. Delange F, Bastani S, Benmiloud M. Definitions of endemic goiter and cretinism, classification of goiter size and severity of endemias, and survey techniques. In: Dunn JT, Pretell EA, Daza CH, Viteri FE, editors. Towards the Eradication of Endemic Goiter, Cretinism, and lodine Deficiency. Washington, DC: Pan American Health Organization; 1986. p. 373-6.

5. Kalra S, Kalra B, Sharma A. Prevalence of type 1 diabetes mellitus in Karnal district, Haryana state, India. Diabetol Metab Syndr 2010;2:14.

6. Kakleas K, Paschali E, Kefalas N, Fotinou A, Kanariou M, Karayianni C, et al. Factors for thyroid autoimmunity in children and adolescents with type 1 diabetes mellitus. Ups J Med Sci 2009;114:214-20.

7. Kakleas K, Karayianni C, Critselis E, Papathanasiou A, Petrou V, Fotinou $A$, et al. The prevalence and risk factors for coeliac disease among children and adolescents with type 1 diabetes mellitus. Diabetes Res Clin Pract 2010;90:202-8.

8. Bhadada SK, Kochhar R, BhansaliA, Dutta U, Kumar PR, Poornachandra KS, et al. Prevalence and clinical profile of celiac disease in type 1 diabetes mellitus in north India. J Gastroenterol Hepatol 2011;26:378-81.

9. De Block CE, De Leeuw IH, Van Gaal LF. Autoimmune gastritis in type 1 diabetes: A clinically oriented review. J Clin Endocrinol Metab 2008;93:363-71.

10. Agrawal S, Desai MP. Simultaneous occurrence of type I diabetes mellitus and juvenile rheumatoid arthritis. Indian Pediatr 2003;40:568-71.

11. Hanas R, Donaghue KC, Klingensmith G, Swift PG. ISPAD clinical practice consensus guidelines 2009 compendium. Introduction. Pediatr Diabetes 2009;10 Suppl 12:1-2.

How to cite this article: Gutch M, Kumar S, Saran S, Gupta KK, Mohd Razi S, Philip R. Prevalence of autoimmune disorders in pediatrics type-1 diabetes mellitus in western, Uttar Pradesh, India. Int J Med Public Health 2015;5:29-31.

Source of Support: Nil, Conflict of Interest: None declared. 